\title{
Visualisasi Perkembangan Janin Manusia menggunakan Augmented Reality dengan teknik Single Marker Multi Object
}

\author{
Human Fetus Growth Visualization with Augmented Reality using Single Marker Multi Object \\ Technique
}

\author{
Andria Kusuma Wahyudi ${ }^{1}$, Irma Natalia Pangau ${ }^{2}$ \\ ${ }^{1,2}$ Teknik Informatika, Fakultas Ilmu Komputer, Universitas Klabat Indonesia \\ Email : ${ }^{1}$ andriawahyudi@ unklab.ac.id, ${ }^{2} 11310287 @$ student.unklab.ac.id
}

\begin{abstract}
Abstrak
Embriologi adalah bagian dari cabang ilmu pengetahuan alam biologi yang mempelajari tentang perkembangan embrio atau calon janin dalam rahim. Dimana usia dari calon janin di dalam kandungan dihitung saat seorang wanita telah dibuahi oleh sperma pria dalam kurun waktu tujuh hari sebelum ovulasi. Media pembahasan mengenai perkembangan janin di dalam kandungan terdapat di buku-buku pelajaran, artikel umum, dan website khusus ibu hamil kurang menarik minat karena terlalu banyak teks dan memiliki tampilan belum atraktif. Paper ini menggunakan teknologi Augmented Reality yang dapat merealisasikan dunia virtual ke dunia nyata secara real-time sebagai media pembahasan yang dapat memberikan kemudahan dalam memberikan informasi mengenai perkembangan janin didalam kandungan. Dengan menggunakan teknologi Augmented Reality, maka pengguna dapat menggunakan kamera smartphone berbasis Android untuk menangkap marker yang dapat memperlihatkan objek virtual pada dunia nyata. Dalam pembahasan paper ini, kami menggunakan single marker multi object sehingga marker yang diperlukan cukup satu saja untuk menampilkan semua objek 3D yang ada. Aplikasi visualisasi pengenalan perkembangan janin manusia dalam kandungan menggunakan teknologi Augmented Reality dapat memberikan informasi yang dapat ditangkap dengan mudah bagi pengguna mulai dari kalangan remaja hingga orang dewasa.
\end{abstract}

Kata Kunci - Embrio, Janin, Augmented Reality, Marker, Objek Virtual

\section{Abstract}

Embryology is part of the branch of biological science that studies the development of embryos or fetal candidates in the womb. Where the age of the fetal candidate in the womb is calculated when a woman has been fertilized by a male sperm within seven days before ovulation. Media discussion of the development of the fetus in the womb contained in textbooks, general articles, and special websites pregnant women are less attractive because of too much text and has a look not yet attractive. This paper uses Augmented Reality technology that can realize the virtual world to the real world in real-time as a medium of discussion that can provide convenience in providing information about the development of the fetus in the womb. By using Augmented Reality technology, users can use Android-based smartphone camera to capture markers that can show virtual objects in the real world. In the discussion of this paper, we use a single multi-object marker so that the required markers are sufficient to display all $3 D$ objects. The visualization of the introduction of human fetal development in the womb using Augmented Reality technology can provide information that can be easily captured for users ranging from teenagers to adults.

Keywords - Embryo, Fetal, Augmented Reality, Marker, Virtual Object. 


\section{PENDAHULUAN}

Embriologi merupakan salah satu bagian dari cabang ilmu pengetahuan alam biologi yang mempelajari tentang perkembangan embrio atau calon janin dalam rahim. Pada manusia, embrio mulai berkembang dari zigot atau sel tunggal disaat sperma dan ovum menyatu dalam rahim wanita dan menciptakan peristiwa fertilisasi atau pembuahan. Sperma dihasilkan di testis sedangkan ovum dihasilkan dari ovarium. Peristiwa fertilisasi pada manusia terjadi pada tubuh wanita.

Media pembahasan mengenai perkembangan janin manusia terdapat di buku - buku pelajaran, artikel umum dan website khusus ibu hamil. Mustika [1] mengatakan bahwa pembahasan yang biasa ditampilkan di dalam buku menggunakan teks dan gambar kurang menarik dikarenakan terlalu banyaknya teks penjelasan dan kurangnya gambar. Begitu juga dengan media website yang diharuskan terhubung ke jaringan internet, dengan tampilan interface yang tidak menarik minat masyarakat baik itu dari kalangan remaja maupun orang dewasa.

Dalam paper ini kami mencoba membuat sebuah cara baru dalam mempelajari perkembangan janin manusia di dalam kandungan. Salah satu cara untuk menampilkannya adalah dengan Augmented Reality. Augmented Reality atau AR merupakan teknologi yang memungkinkan penambahan objek virtual pada dunia nyata, dan untuk melihat objek virtual diperlukan berupa perangkat kamera smartphone. Penambahan objek virtual dapat dilakukan dengan metode marker-based atau markeless.

Adapun beberapa penelitian yang menggunakan AR[2][3] dan penelitian mengenai aplikasi perkembangan janin. Salah satunya adalah sebagai media dalam mempermudah proses belajar mengajar oleh Wahyudi, Ferdiana dan Hartanto [2] telah berhasil membuat sebuah buku interaktif sebagai media pengenalan dan pembelajaran candi prambanan menggunakan AR dengan menerapkan berbagai macam kondisi pelacakan dan pendeteksian marker, mengidentifikasi pendeteksian minimum sesuai perangkat yang digunakan, dan mengidentifikasi requirement untuk menggunakan ARca. Hidayat [4]telah berhasil membuat aplikasi AR sebagai alternatif penyampaian materi kesehatan gigi kepada peserta didik yang dapat digunakan untuk memperluas wawasan masyarakat umum tentang teknologi informasi. Syahrir [5]meneliti bahwa dengan menggunakan AR para siswa dapat secara langsung mengamati objek tiga dimensi sehingga metode pembelajaran struktur rangka manusia menjadi lebih menarik. Penelitian yang dilakukan oleh Saputro dan Saputra [6]adalah penerapan AR mampu merealisasikan dunia virtual ke dunia nyata, dapat menampilkan objek - objek gambar dua dimensi menjadi tiga dimensi sehingga metode pembelajaran tidaklah monoton dan anak - anak jadi terpacu untuk mengetahui bentuk dan visualisasi dari organ pencernaan manusia. Edson dalam penelitianya berhasil merancang visualisasi 3D situs bersejarah Indonesia[7]. Menurut Tutik dan Sri [3] bahwa aplikasi pertumbuhan janin manusia dalam kandungan sangat memudahkan guru dan siswa dalam mempelajari pertumbuhan janin manusia dalam kandungan.

Dari penelitian sebelumnya, maka dapat dibuktikan bahwa menggunakan teknologi AR yang menerapkan berbagai macam kondisi pelacakan pada marker, dapat mempermudah guru dalam menerangkan pelajaran, menarik minat belajar dari siswa dan memperluas wawasan masyarakat umum. Penelitian terbaru menemukan bahwa penambahan objek 3D terhadap dunia nyata dapat memberikan pengalaman yang signifikan bagi pengguna[8][9]. Adapun ditemukan penelitian penelitian sebelumnya pada umumnya menggunakan multi marker. Dalam penelitian ini dirancang menggunakan satu marker saja namun dengan object 3D yang lebih dari satu sehingga mengoptimalkan penggunaan marker. 
Dengan memanfaatkan kesempatan teknologi AR, maka dirancanglah sebuah aplikasi berbasis Android dengan tampilan simple dan menarik dengan tujuan untuk menampilkan dan mengenalkan perkembangan janin manusia dalam kandungan kepada masyarakat mulai dari remaja hingga orang tua. Tujuan penelitian ini adalah untuk membuat suatu aplikasi visualisasi pengenalan tentang perkembangan janin manusia dalam kandungan bagi pengguna menggunakan teknologi Augmented Reality pada smartphone berbasis Andriod.

\section{METODE PENELITIAN}

Dalam meyelesaikan masalah penelitian ini, beberapa langkah yang perlu dilakukan dalam metode penelitian sebagai berikut:

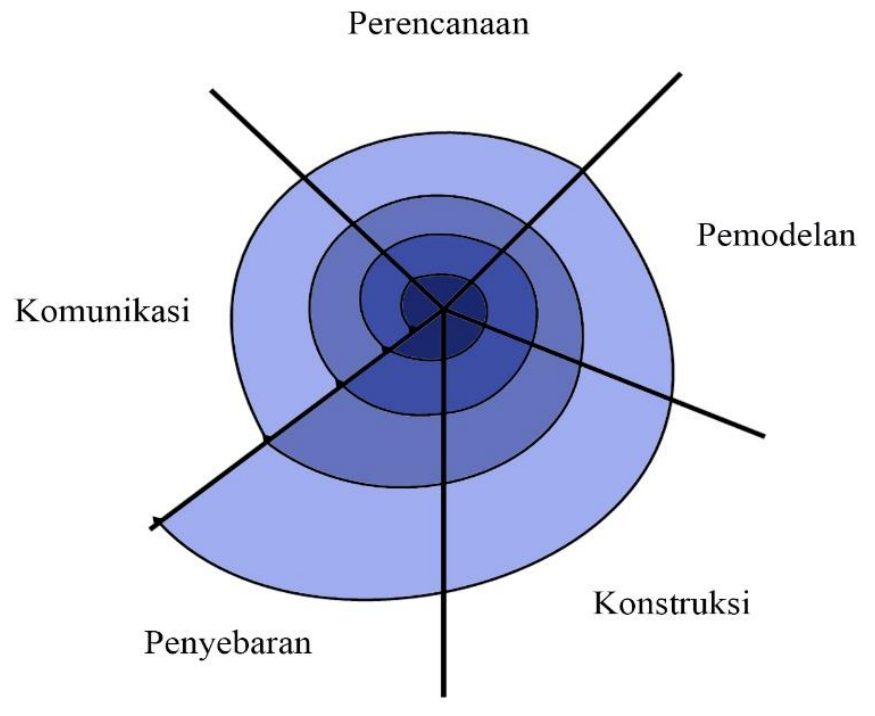

Gambar 1. Kerangka Konseptual Penelitian Model Spiral

Pada Gambar 1 diatas terdapat beberapa tahapan dalam penelitian yang dilakukan, Berikut Penjelasannya:

1. Komunikasi

Pada tahap ini, kami mulai melakukan komunikasi dengan dr. Henry Suak sebagai Dokter Radiologi Rumah Sakit Advent Manado. Kami memulai penelitian dengan cara studi literatur dan wawancara kepada Dokter Radiologi untuk menentukan kebutuhan yang dibutuhkan dalam pembuatan aplikasi visualisasi AR pada pengenalan perkembangan janin manusia dalam kandungan serta menentukan fitur dan fungsi aplikasi.

2. Perencanaan

Setelah data didapat, maka selanjutnya dibuatlah perkiraan waktu yang dibutuhkan serta penjadwalan tugas - tugas yang akan dilaksanakan dalam pembuatan aplikasi. Ditahap ini juga dihitung biaya yang akan dikeluarkan dan menganalisa resiko yang akan terjadi selama pembuatan aplikasi.

3. Pemodelan

Selanjutnya menganalisis cara kerja dari aplikasi menggunakan use case, class diagram, seqguence diagram dan activity diagram menggunakan aplikasi Edraw Max, membuat perancangan arsitektur, mengunggah vuforia database, pembuatan object $3 D$ dan interface menggunakan aplikasi Blender sesuai dengan cara kerja yang sudah dianalisa sebelumnya.

4. Pengkodean Aplikasi 
Ditahap ini dilakukan penulisan kode untuk membangun aplikasi dari hasil analisis cara kerja dan rancangan awal aplikasi dengan menerjemahkan rancangan awal ke dalam kode program menggunakan aplikasi Unity. Kami melakukan pengkodean dengan menggunakan bahasa pemrograman C\#.

5. Penyebaran

Pada tahap akhir ini, kami melakukan pengujian dan evaluasi oleh stakeholders yaitu Dokter Radiologi dari Rumah Sakit Advent Manado dengan memberikan penilaian terhadap aplikasi yang telah dibuat. Kami menguji prototype aplikasi memakai teknik pengujian blackbox dimana kami menguji fungsionalitas dari aplikasi. Pengujian dilakukan agar mendapat tanggapan atau respon dari pengguna.

\section{HASIL DAN PEMBAHASAN}

Perancangan system yang digunakan dalam penelitian ini adalah 4 jenis UML, yaitu: Use Case, Clas Diagram, Activity Diagram, dan Sequence Diagram dengan penjelasan gambar sebagai berikut:

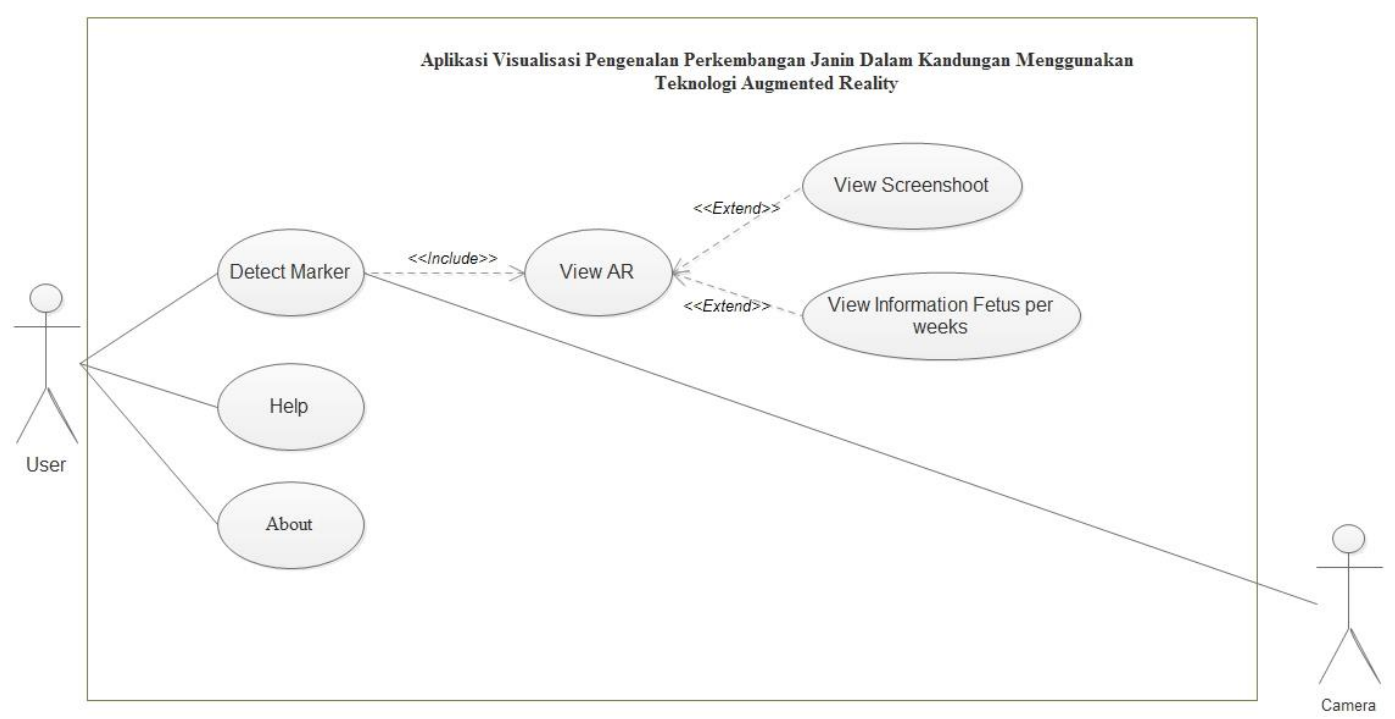

Gambar 2. Use Case Diagram

Gambar 2 adalah gambar use case dimana user dan camera sebagai actor. User menggunakan kamera smartphone untuk mendeteksi marker yang dapat menampilkan AR. User dapat melihat serta menyimpan informasi mengenai janin perminggu. User juga dapat melihat petunjuk penggunaan aplikasi. 

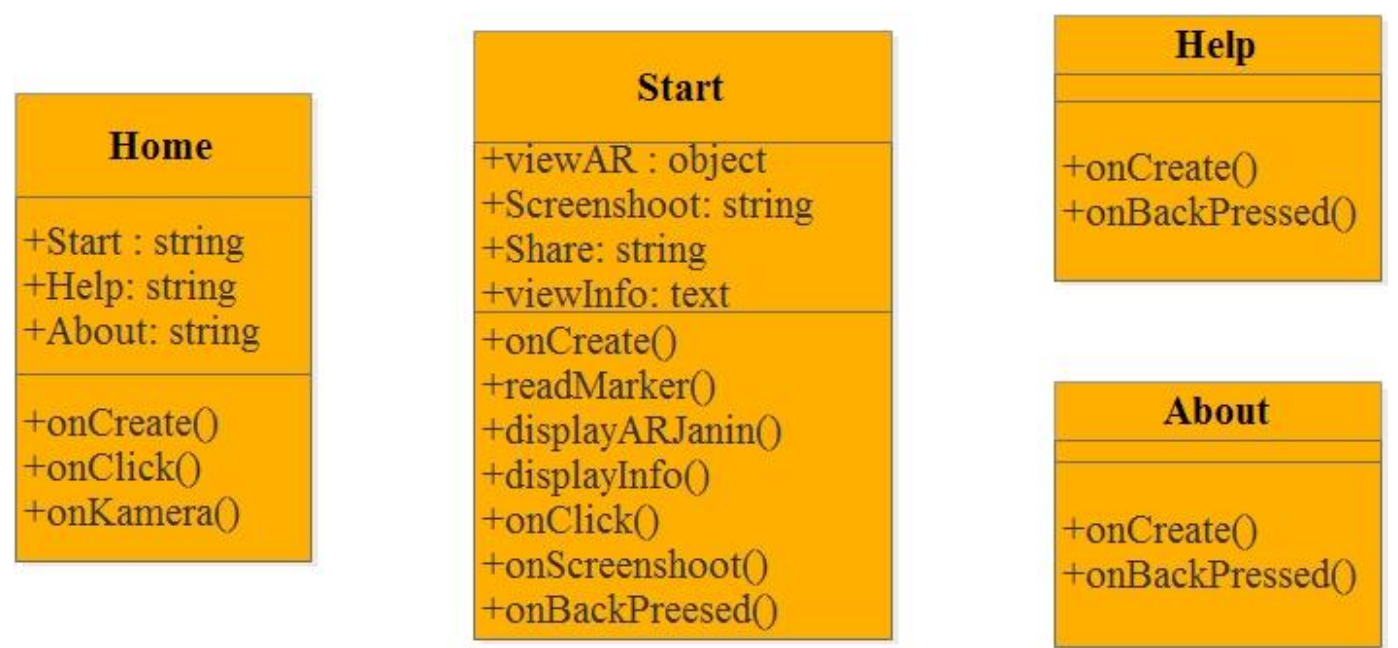

\section{Gambar 3. Class Diagram}

Pada Gambar 3 dapat dilihat Class Diagram dari aplikasi yang akan dibuat oleh peneliti yang terdiri dari 4 class yaitu class Home, Start, Help dan About.

1. Class Home adalah class halaman pertama dari aplikasi yang memiliki tiga pilihan yaitu : Start, Help, dan About. Class ini juga memiliki fungsi onCreate() yang akan dijalankan pertama kali saat class ini dijalankan dan menampilkan user interface dari aplikasi. Kemudian class ini juga memiliki fungsi onClick() untuk memberikan action terhadap button yang di tekan, onKamera() untuk mengakses kamera.

2. Class Start adalah class utama dari aplikasi yang akan menampilkan visualisasi perkembangan janin dalam bentuk tiga dimensi Augmented Reality. Dalam class ini terdapat fungsi onCreate() yang akan dijalankan pertama kali saat class ini dijalankan, fungsi readMarker() untuk membaca marker, fungsi displayARJanin() untuk melihat objek 3D, fungsi displayInfo() untuk melihat infor dari 3D janin, onclick() untuk memberikan action terhadap button yang di tekan, onScreenshoot() untuk menyimpan gambar hasil capture interface, dan fungsi onBackPressed() untuk kembali ke halaman sebelumnya.

3. Class Help, memiliki fungsi onCreate() untuk menampilkan tampilan Help dan fungsi onBackPressed() untuk kembali ke menu utama jika menekan button back.

4. Class About, memiliki fungsi onCreate() untuk menampilkan tampilan about dan fungsi onBackPressed() untuk kembali ke menu utama jika menekan button back. 


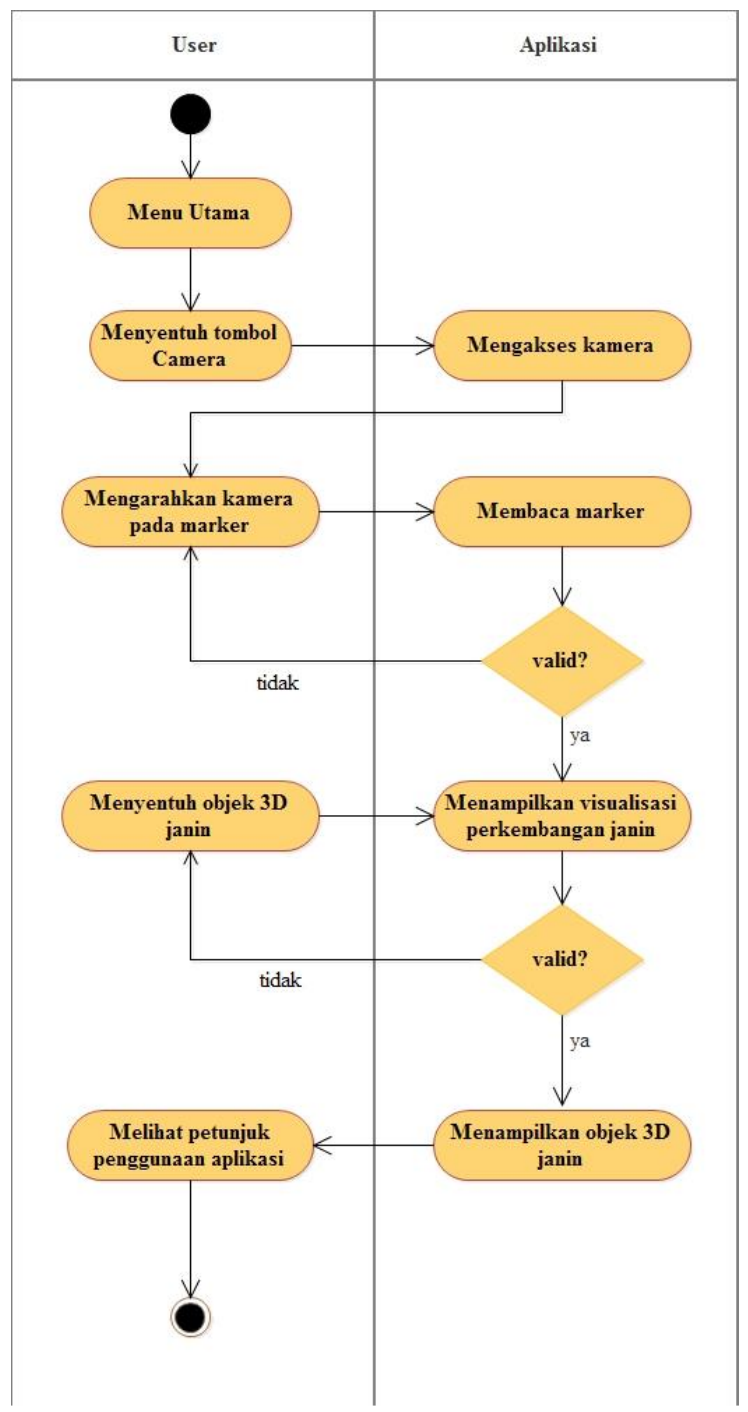

Gambar 4. Activity Diagram dari Detect Marker, View AR, dan View Information Fetus per weeks

Gambar 4 mengenai activity diagram dari Detect Marker, View AR dan View Information Fetus per weeks.

1. User akan masuk pada menu utama dan menyentuh tombol start untuk mengakses kamera smartphone.

2. Setelah itu, user harus mengarahkan kamera smartphone pada marker yang telah disiapkan. Jika objek belum muncul, maka user harus mengarahkan kamera smarphone dengan benar ke marker.

3. User dapat memilih objek yang ingin ditampilkan beserta infomasinya.

4. Jika user belum mengerti tentang penggunaan aplikasi, user dapat kembali ke menu utama untuk memilih menu help untuk melihat petunjuk penggunaan aplikasi. 


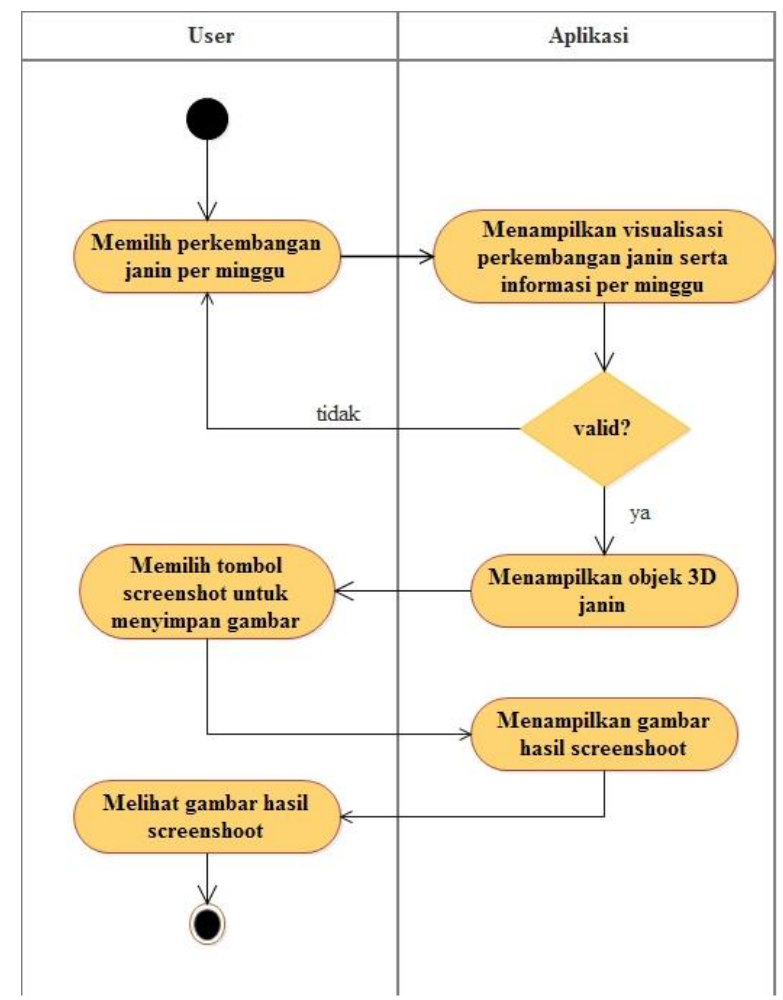

Gambar 5. Activity Diagram View Screenshoot

Gambar 5 merupakan activity diagram view screenshoot dimana user ingin menyimpan informasi AR dalam bentuk format .jpg dengan menekan tombol screenshoot.

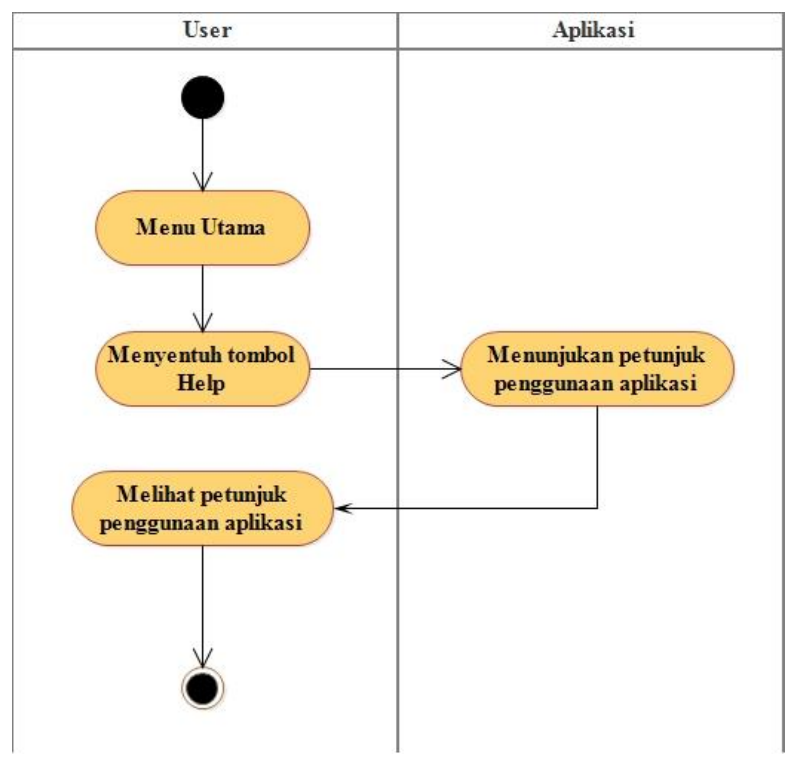

Gambar 6. Activity Diagram Help

Gambar 6 mengenai activity diagram help bertujuan untuk memberikan petunjuk penggunaan aplikasi kepada user. 


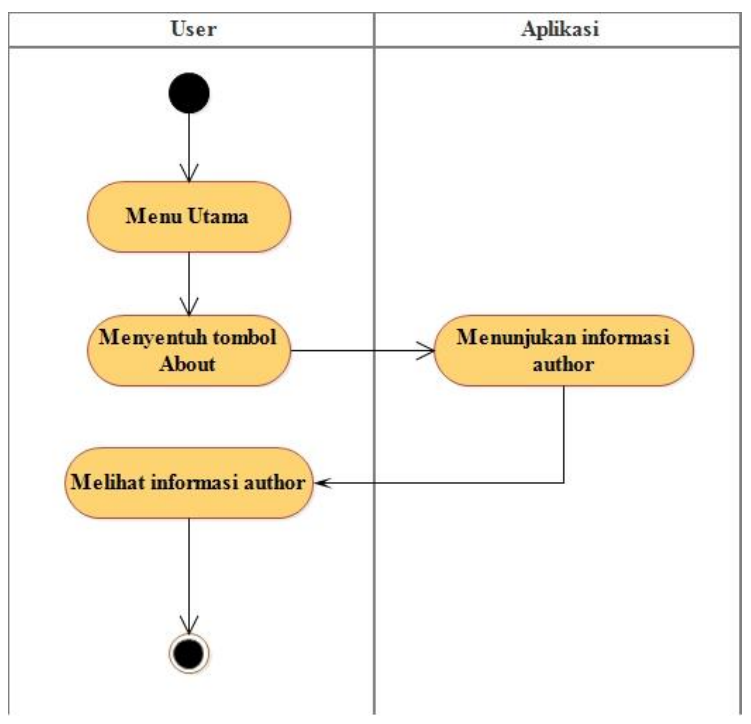

Gambar 7. Activity Diagram About

Gambar 7 mengenai activity diagram about bertujuan untuk memperlihatkan informasi kepada user.

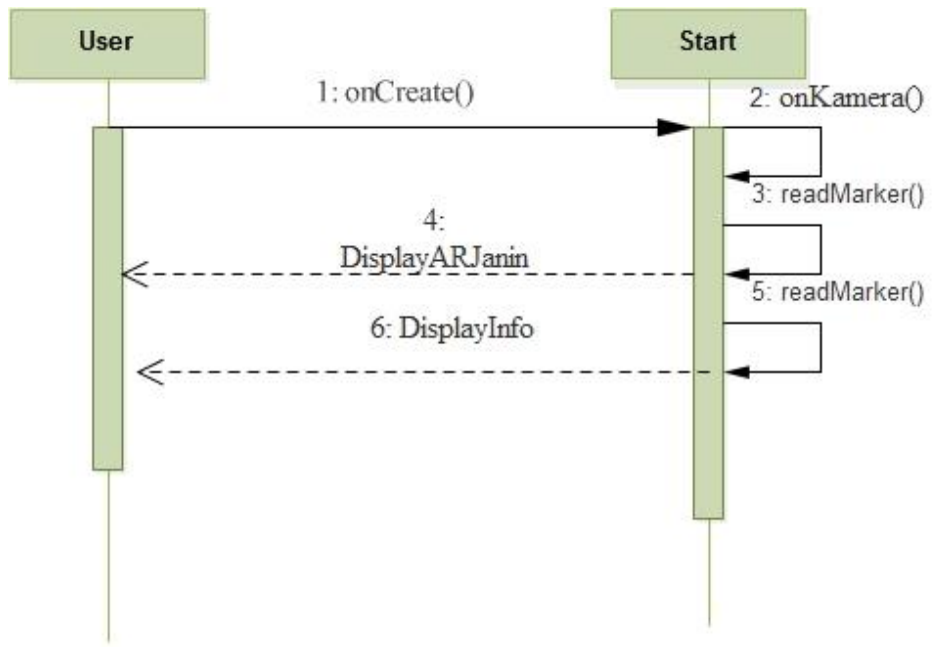

Gambar 8. Sequence Diagram menu start

Pada Gambar 8 menjelaskan Sequence diagram untuk menu start. Pada saat user menekan tombol start dengan metode onCreate() maka sistem akan langsung mengaktifkan kamera dengan cara memanggil metode onKamera(). Kemudian dengan melalui kamera tersebut sistem akan membaca marker. Jika marker terdeteksi dengan baik, maka aplikasi akan menampilkan kepada user 3D Augmented Reality serta informasi perkembangan janin dalam kandungan 


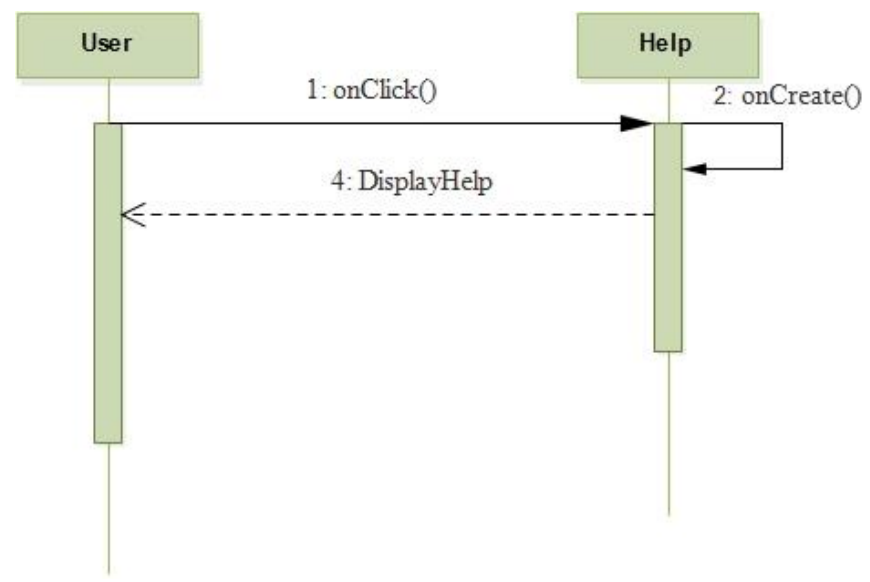

Gambar 9. Sequence Diagram menu Help

Pada Gambar 9 adalah Sequence Diagram dari menu help. Pada saat user menekan tombol help dengan metode onClick(), maka sistem akan menunjukan petunjuk penggunaan aplikasi.

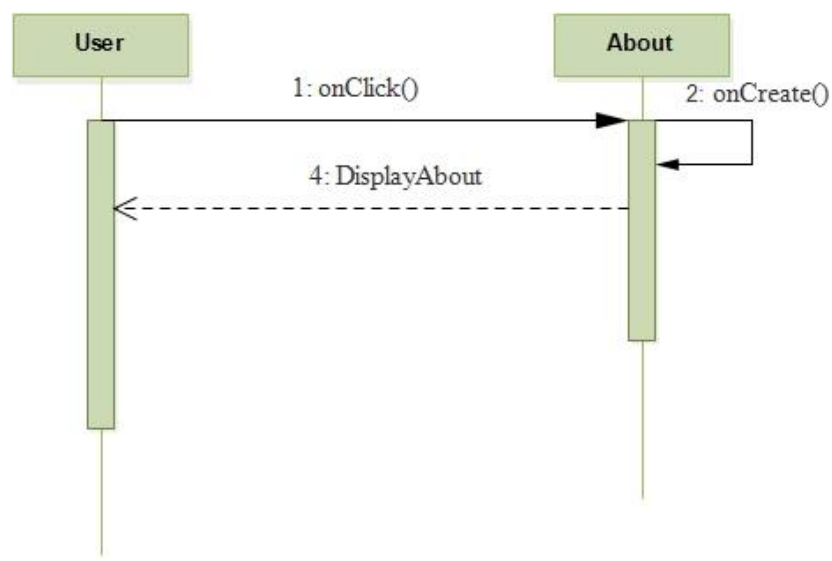

Gambar 10. Sequence Diagram menu About

Pada Gambar 10 adalah Sequence diagram dari menu about. Pada saat user menekan tombol about dengan metode onClick(), maka sistem akan menunjukan informasi tentang pembuat aplikasi. 


\subsection{Desain Antarmuka}

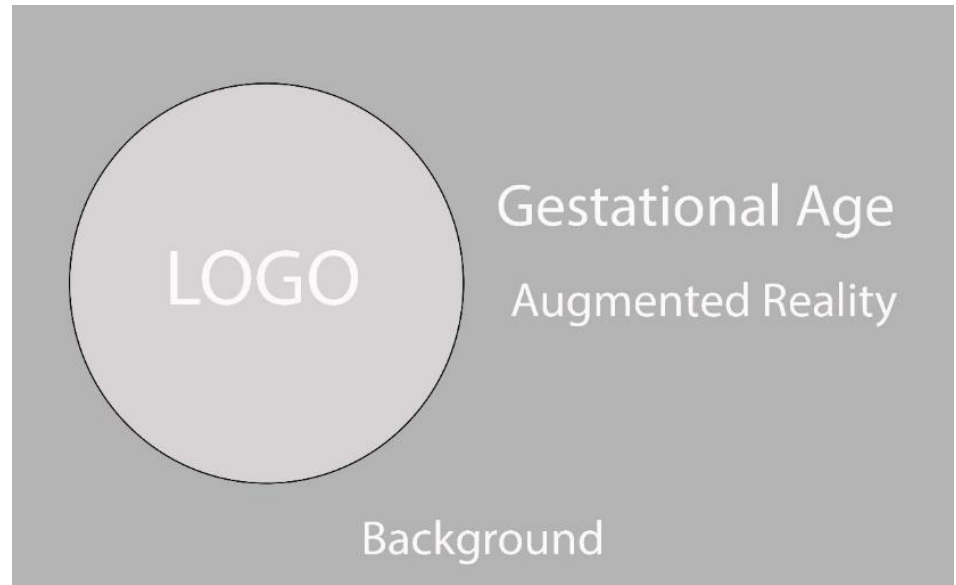

Gambar 11. Spalsh Screen

Pada gambar 11 merupakan tampilan splash screen ketika aplikasi diakses oleh user.

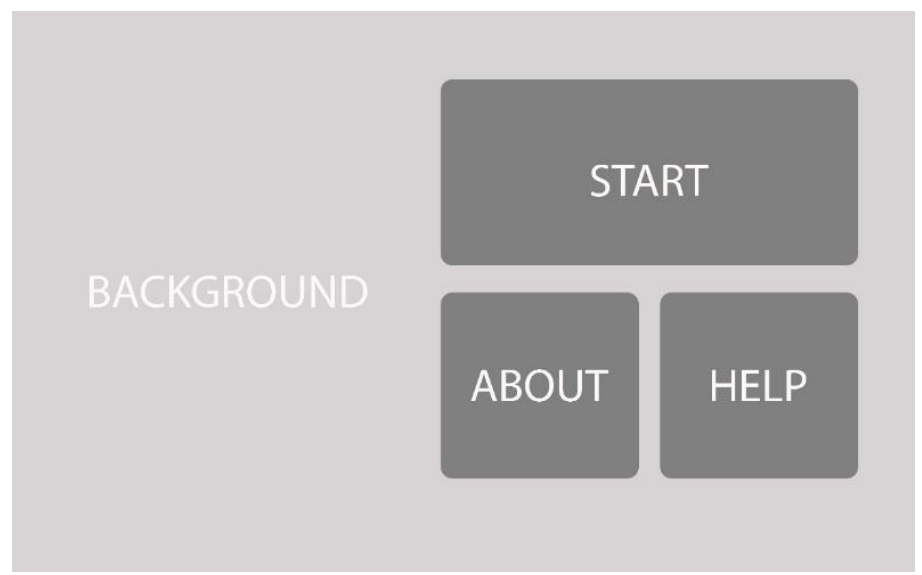

Gambar 12. Rancangan Tampilan Main Menu

Pada gambar 12 merupakan rancangan antarmuka untuk Main Menu dimana pada tampilan ini terdapat tiga menu yaitu icon Start, Help, dan About sebagai button dari menu Start untuk mengakses kamera dari smartphone.

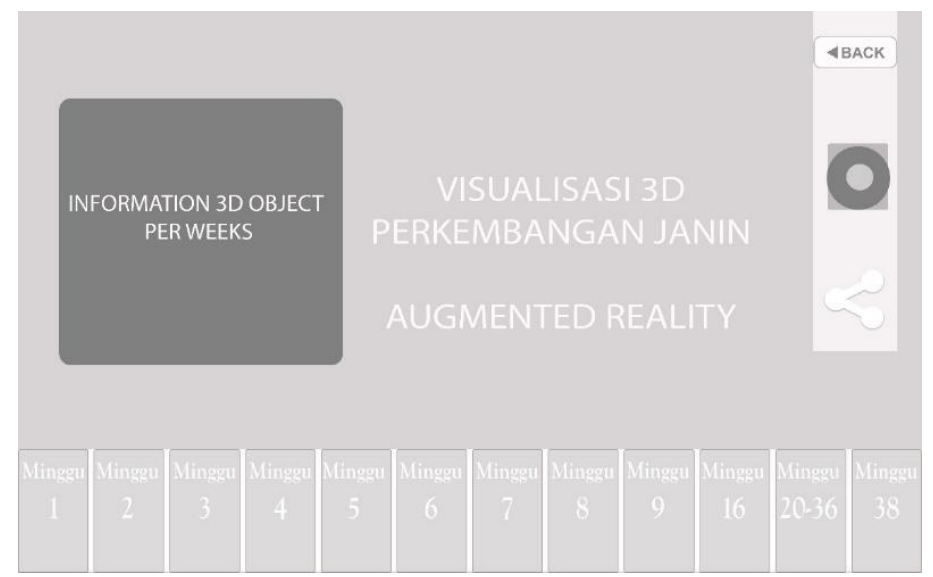

Gambar 13. Menu Start 
Pada Gambar 13 terdapat rancangan antarmuka dari menu start atau augmented reality yang dimana ketika user mengakses menu start, maka aplikasi akan langsung mengakses kamera pada smartphone, dan ketika diarahkan pada markerless maka akan ditampilkan visualisasi perkembangan janin dalam bentuk tiga dimensi autmented reality.

Setelah markerless ditangkap oleh smartphone, maka aplikasi akan menampilkan 3D janin. User dapat dapat menekan tanda yang terletak dibagian tengah paling bawah pada tampilan aplikasi untuk mengarahkan user ke 3D sebelumnya ataupun selanjutnya. User juga dapat men-screenshoot tampilan dari keseluruhan 3D janin agar dapat di simpan dalam galeri smartphone

\subsection{Tampilan Antarmuka}

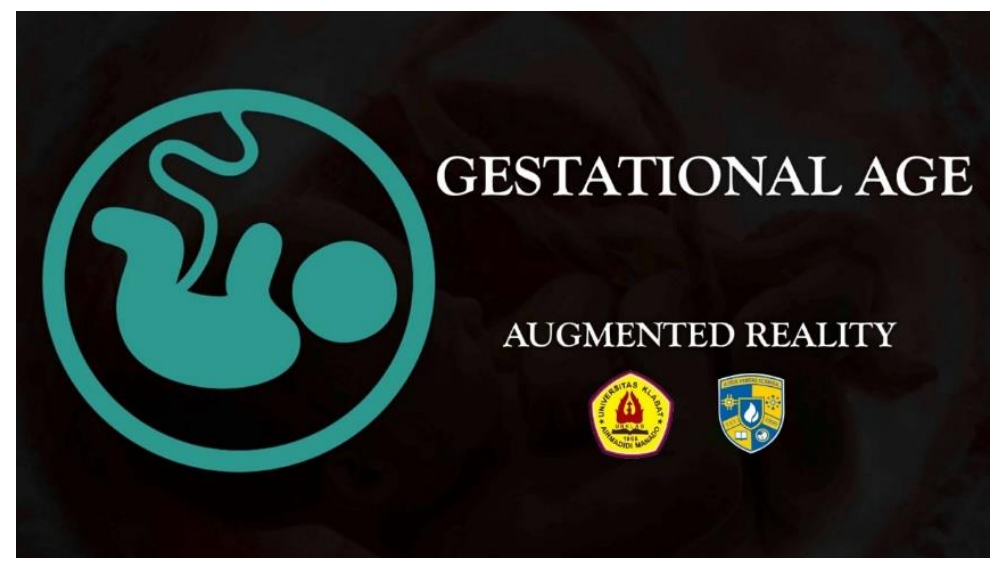

Gambar 14. Tampilan Splash Screen

Gambar 14 merupakan tampilan awal dari aplikasi pada saat aplikasi dibuka.

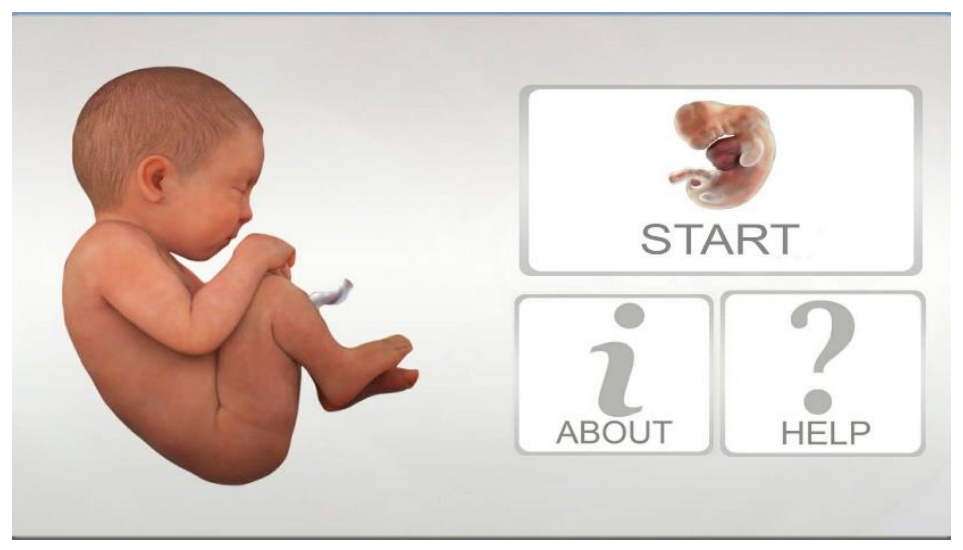

Gambar 15. Tampilan Main Menu

Gambar 15 merupakan tampilan halaman main menu. Halaman ini akan ditampilkan setelah splash screen selesai. Pada halaman main menu ini terdapat tiga button antara lain:

1. Button Start merupakan augmented reality yang menampilkan visualisasi pengenalan perkembangan janin dalam kandungan.

2. Button about memberikan informasi dari pembuat aplikasi.

3. Button Help menjelaskan tentang penggunaan aplikasi. 


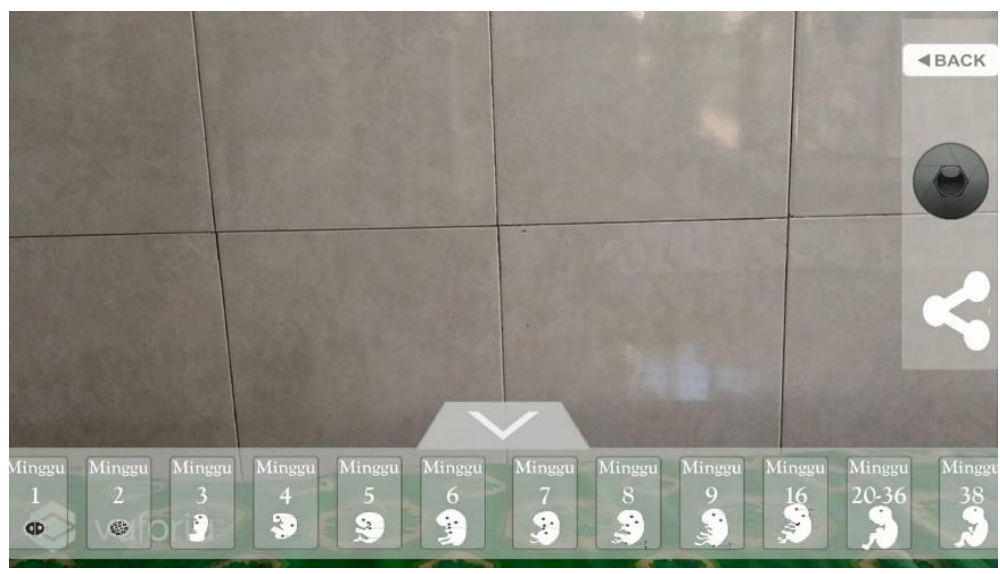

Gambar 16. Deteksi Markerless

Gambar 16 merupakan tampilan pada sat augmented reality dijalankan tetapi markless belum terdeteksi. Setelah markerless terdeteksi maka akan muncul pada layar augmented reality visualisasi perkembangan janin dalam kandungan seperti pada gambar 16 diatas.

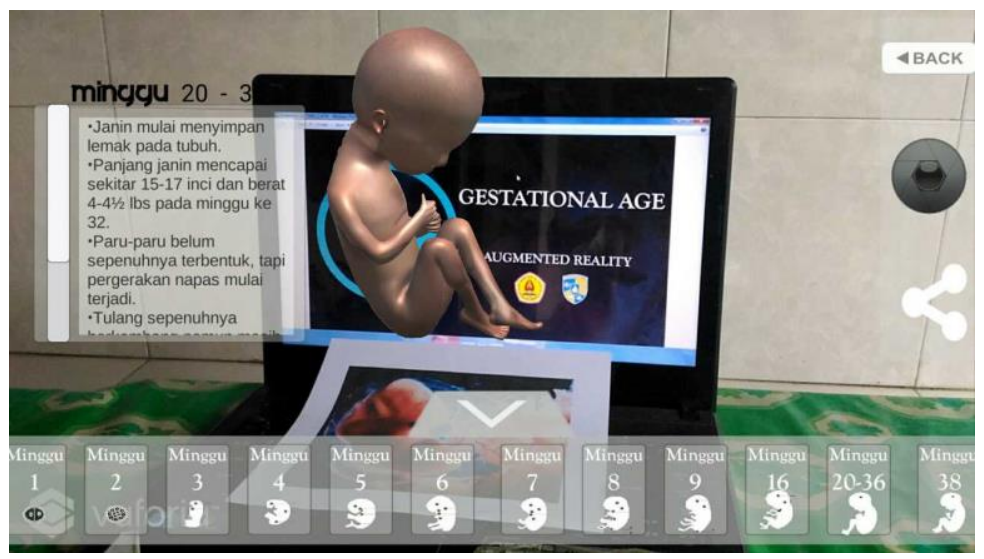

Gambar 17. Gestational Age Augmented Reality

Gambar 17 diatas merupakan tampilan pada saat user menyentuh button per weeks dalam keadaan augmented reality sedang aktif, maka secara otomatis akan menampilkan informasi dan objek perkembangan janin dalam kandungan.

\section{KESIMPULAN}

Apliksi dapat menampilkan visualisasi perkembangan janin dalam kandungan dan data menampilkan informasi dari setiap objek janin. Penggunakan teknik single marker membuat marker yang di gunakan cukup satu saja yang kemudian dapat menampilkan semua objek dalam satu marker tersebut dengan algoritma kami tanpa harus menggunakan marker yang banyak. Jika marker tidak terdeteksi dengan baik maka akan diperlukan pencahayaan yang lebih terang lagi. Pada saat membuka tampilan kamera akan membutuhkan sedikit waktu, karena proses rendering dari setiap objek dilakukan pada saat menu Start dibuka. Aplikasi ini bisa dijalankan pada Andriod dengan API level minimal 14 atau versi 4.2 (Jelly Bean). Aplikasi diharapkan dapat digunakan sebagai perangkat visualisasi untuk menampilkan pembelajaran janin.

\section{SARAN}

Saran untuk penelitian ini antara lain yaitu dengan melengkapi objek janin dalam kandungan. Aplikasi dapat dibuat pada platform yang lain. Menambahkan animasi pada objek janin. Dan melakukan 
pengujian pada pengguna kemudian dilakukan survey untuk melilai seberapa baik penerapan aplikasi ini dalam pembelajaran yang sesungguhnya.

\section{UCAPAN TERIMA KASIH}

Penulis mengucapkan terima kasih kepada Fakultas Ilmu Komputer Universitas Klabat yang telah memberi dukungan terhadap penelitian ini, dan kepada dr. Henry Suak sebagai Dokter yang melakkan validasi aplikasi ini.

\section{DAFTAR PUSTAKA}

[1] M. Mustika, C. G. Rampengan, R. Sanjaya, and S. Sofyan, "Implementasi Augmented Reality Sebagai Media Pembelajaran Interaktif," Creat. Inf. Technol. J., vol. 2, no. 4, pp. 277-291, 2015.

[2] A. Wahyudi, "ARca: Perancangan Buku Interaktif Berbasis Augmented Reality pada Pengenalan dan Pembelajaran Candi Prambanan dengan Smartphone Berbasis Android," J. Nas. Tek. Elektro Dan Teknol. Inf. JNTETI, vol. 3, Feb. 2014.

[3] T. Susiani and S. Siswanti, "Visualisasi Pertumbuhan Janin Dalam Rahim Manusia sebagai Alternatif Media Pembelajaran," J. Ilm. SINUS, vol. 10, no. 1, Dec. 2013.

[4] T. Hidayat, "Penerapan Teknologi Augmented Reality Sebagai Model Media Edukasi Kesehatan Gigi Bagi Anak," Creat. Inf. Technol. J., vol. 2, no. 1, pp. 77-92, 2014.

[5] A. S. Syahrir, "Visualisasi Struktur Rangka Manusia Berbasis Augmented Reality untuk Mata Pelajaran IPA pada SD Negeri 1 Daya Makassar," Proc. Konf. Nas. Sist. Dan Inform. KNSI, vol. 0, no. 0, Oct. 2015.

[6] R. E. Saputro and D. I. S. Saputra, "Pengembangan Media Pembelajaran Mengenal Organ Pencernaan Manusia Menggunakan Teknologi Augmented Reality," J. Buana Inform., vol. 6, no. 2, May 2015.

[7] Y. P. Edson, A. Wahyudi, and C. Dumingan, "A Proposed Combination of Photogrammetry, Augmented Reality and Virtual Reality Headset for heritage visualisation," in 2016 International Conference on Informatics and Computing (ICIC), Lombok, Indonesia, 2016, vol. 1, pp. 43-48.

[8] T. Chatzidimitris, D. Gavalas, and D. Michael, "SoundPacman: Audio augmented reality in locationbased games," in 2016 18th Mediterranean Electrotechnical Conference (MELECON), 2016, pp. 1-6.

[9] A. K. Wahyudi, R, Tatangin, "Aplikasi Wisata 3D Virtual First Person View(FPV) Pantai Lakban Ratatotok," Eksplora Informatika., vol. 6, no. 2, Mar. 2017. 